\title{
Referral Process in Patients with Uveitis: A Challenge in the Health System
}

This article was published in the following Dove Press journal:

Clinical Ophthalmology

\author{
Alejandra Villalobos- \\ Pérez (D) ${ }^{1, *}$ \\ Juliana Reyes-Guanes (iD) $2, *$ \\ Juliana Muñoz-Ortiz (D) 2,3 \\ María Andrea Estévez- \\ Florez iD ${ }^{3}$ \\ Mario Ramos-Santodomingo (iD ${ }^{3}$ \\ Valentina Balaguera-Orjuela ${ }^{3}$ \\ Alejandra de-la-Torre (iD) ${ }^{3}$ \\ 'Universidad del Norte, Barranquilla, \\ Colombia; ${ }^{2}$ Escuela Barraquer. Research \\ Group, Escuela Superior de Oftalmología \\ del Instituto Barraquer de América, \\ Bogotá, Colombia; ${ }^{3}$ Research Group in \\ Neuroscience NeURos, Escuela de \\ Medicina y Ciencias de la Salud, \\ Universidad del Rosario, Bogotá, \\ Colombia
}

*These authors contributed equally to this work
Purpose: To describe the evaluation and referral process from a group of patients with uveitis presented at a specialized uveitis center in Bogotá, Colombia.

Methods: An observational descriptive cross-sectional study was performed. After applying the selection criteria, 315 clinical records were recovered. Univariate and bivariate analyses were used, reporting proportions, means and standard deviations.

Results: The mean age of the sample was 45.23 years old and $63.8 \%$ of them were females. Patients were mostly referred by retina specialists, general ophthalmologists, rheumatologists, and cornea specialists. Meantime between the first ocular symptom and uveitis specialist evaluation was 2.08 years. Patients had been previously evaluated by a mean of 1.9 ophthalmologists. In $79.9 \%$ of patients, inflammation was recognized by the remittent; however, only $4.7 \%$ of patients were correctly graded according to SUN classification. At first time consultation with the uvea specialist, $52.1 \%$ of the patients arrived with an adequate infectious panel, $58.1 \%$ with an adequate rheumatologic panel, $11.6 \%$ with aqueous humor PCR study, $65.1 \%$ with an initial etiological diagnosis, $34.9 \%$ with inadequate topical treatment, and $59.6 \%$ with inadequate systemic treatment. The mean time to reach a diagnosis by the uvea specialist was 5.27 weeks ( 0.10 years). A diagnostic coincidence was not reached in $58.7 \%$ of the cases.

Conclusion: The referral process to uveitis specialists is complex but highly relevant for those who suffer from this pathology. Health professionals must be aware of the standardized classification of the disease, the appropriate treatment according to the classification, and early referral to the uveologist with adequate laboratory tests.

Keywords: uveitis, referral and consultation, ophthalmologists, disease management, diagnosis, Colombia

\section{Plain Language Summary}

Uveitis is an ocular inflammatory disease that can be caused by infectious and noninfectious etiologies. Due to its complexity, many cases are not easily recognized, which may lead to complications. This is why this pathology must be treated by an ophthalmologist specialized in the disease, a uveitis specialist. We consider it is crucial to study the referral process to the uveitis specialist and its possible role in the disease. The aim of this article is to describe the evaluation and referral process from a group of patients with uveitis presented at a specialized uveitis center in Bogotá, Colombia. We included 315 patients (63.8\% females) with a mean age of 45.23 years old. Patients were mostly referred by retina specialists and general ophthalmologists. Time elapsed until the uveitis consultation was 2.08 years and patients were previously evaluated from 0 to 6 ophthalmologists. Intraocular inflammation was recognized in $79.9 \%$ of patients but was classified according to
Correspondence: Alejandra de-la-Torre Research Group in Neuroscience NeURos, Escuela de Medicina y Ciencias de la Salud, Universidad del Rosario, Carrera 24 \# 63 C 69, Bogotá, Colombia $\mathrm{Tel}+573102482196$

Email alejadelatorre@yahoo.com
Clinical Ophthalmology 202 I:I5 I-10

(c) (1) (5) 2021 Villalobos-Pérez et al. This work is published and licensed by Dove Medical Press Limited. The full terms of this license are available at https://www.dovepress. (c) ${ }_{\mathrm{BY}} \mathrm{NC}_{\mathrm{N}}$ com/terms.php and incorporate the Creative Commons Attribution - Non Commercial (unported, v3.0) License (http://creativecommons.org/licenses/by-nc/3.0/). By accessing the work you hereby accept the Terms. Non-commercial uses of the work are permitted without any further permission from Dove Medical Press Limited, provided the work is properly
attributed. For permission for commercial use of this work, please see paragraphs 4.2 and 5 of our Terms (https://www.dovepress.com/terms.php). 
a standardized classification in only $4.7 \%$ of the cases. More than a half of the patients were referred with adequate laboratories and $11.6 \%$ with aqueous humor PCR. $53.3 \%$ were referred with an initial etiological diagnosis, $34.9 \%$ with inadequate topical treatment, and $59.6 \%$ with inadequate systemic treatment. The mean time to reach a diagnosis by the uvea specialist was 5.27 weeks. Diagnostic coincidence was not reached in $58.7 \%$ of the cases. This study is important as it leads us to recognize what is failing and what should we improve in the referral process of uveitis patients.

\section{Background}

Uveitis comprises a diverse group of intraocular inflammatory conditions, including a variety of disorders that can involve not only the uvea but also the retina, the optic nerve, and the vitreous. Uveitis can be restricted to the eye or related to systemic diseases. ${ }^{1}$ It can be idiopathic, autoimmune, masquerade or caused by numerous infectious agents. ${ }^{2}$ It can vary regarding its clinical course, treatment, and prognosis. Whereas some forms of uveitis have a limited course and a favorable prognosis, requiring a short-term treatment, other forms have a prolonged course with severe visual compromise, requiring long-term treatment. ${ }^{1}$

Due to the complexity of uveitis cases, many of them are not easily recognized, the diagnosis can be delayed, and this can lead to irreversible complications. That is why this pathology must be treated by a uveitis specialist. ${ }^{3}$

In the Colombian health system, the initial attention of the patient is performed by a general practice physician, who decides if the patient must or must not be evaluated by a specialist, in this case, an ophthalmologist. ${ }^{4}$ The ophthalmologist determines if the patient needs to be evaluated by a subspecialist, in this case, a uveitis specialist. ${ }^{5}$ These evaluations are usually performed in an outpatient setting and appointments can take up to months. Additionally, in Colombia, there are few specialists in uveitis, and they are located in the main cities of the country (Bogotá, Cali, Medellín, and Bucaramanga).

We consider it is crucial to study the phenomenon of referral to the uveitis specialist and its possible role in the outcomes of patients with uveitis.

This article aims to describe the evaluation and referral process from a group of patients with uveitis presented at a specialized uveitis center in Bogotá, Colombia, from the onset of the symptoms to their final diagnosis.

\section{Methods}

\section{Design}

We conducted an observational descriptive cross-sectional study in patients diagnosed with uveitis presented at a reference uveitis center in Bogotá, Colombia.

\section{Population}

Clinical records between 2013 and 2018 were reviewed. Inclusion criteria were 1) patients diagnosed with uveitis, 2) patients referred for the first time to the uveitis consultation, and 3) patients evaluated from 2013 to 2018. Exclusion criteria were 1) patients previously evaluated by another uvea specialist and 2) medical records of patients with incomplete data. After applying inclusion and exclusion criteria, 315 clinical records were recovered.

\section{Data Recollection}

We elaborated and validated a database in Microsoft Excel (Microsoft Corp., Redmond, WA, USA). Variables included in the database were: type of specialist who referred the patient, pertinent diagnosis, treatment and categorization of inflammation and uveitis, time between symptoms and evaluation, consistency between referral doctor and uveitis specialist diagnosis and infectious and rheumatologic requested profiles. Evaluation and categorization of intraocular inflammation and uveitis was taken into account only if the specialist who referred the patient was an ophthalmologist, as they are the only specialist who can assess these findings.

\section{Statistical Analysis}

We statistically analyzed the associations between the outcomes of interest and other variables using classical univariate and bivariate analysis. The Kruskal-Wallis test was used to compare quantitative versus categorical variables, and the chi-square test was used to compare categorical versus categorical variables. Results are described by proportions, means and standard deviations.

\section{Results}

\section{Demographics}

We evaluated 315 clinical records of patients referred to the uveitis consultation. The proportion of female patients was $63.8 \%$. The age varied between 1 and 85 years old, with a mean age of 45.23 years old. More detailed information is shown in Table 1. 
Table I Patients Demographic Description

\begin{tabular}{|c|c|c|}
\hline Variables & \multicolumn{2}{|c|}{ Results } \\
\hline Sample & \multicolumn{2}{|c|}{315 patients } \\
\hline Mean age & \multicolumn{2}{|c|}{$45.23 \pm 20.03$ years } \\
\hline \multirow[t]{2}{*}{ Sex } & Female & $20 \mathrm{I}$ patients $(63.8 \%)$ \\
\hline & Male & II 4 patients (36.19\%) \\
\hline
\end{tabular}

\section{Referring Specialists}

The patients were mostly referred by retina specialists, general ophthalmologists, rheumatologists, and cornea and anterior segment sub-specialists. More detailed information is shown in Table 2.

Time elapsed between the appearance of symptoms and the uveitis specialist's first evaluation varied between 1 and 1042 weeks, with a mean of 108.5 weeks (2.08 years). When evaluating causative diagnosis, infectious uveitis time was shorter than non-infectious uveitis. Unexpectedly, posterior uveitis was the most rapidly referred, followed by intermediate uveitis, panuveitis and anterior uveitis.

Before uveitis first consultation, patients were evaluated by 0 to 6 ophthalmologists, with a mean of $1.9 \pm 1.09$.

Detailed information is shown in Table 2.

\section{Ophthalmological Evaluation}

Since only ophthalmologists count with the tools to perform an adequate ophthalmological examination, the variables of inflammation recognition and classification, and uveitis classification according to the $\mathrm{SUN}^{6}$ were evaluated only if the patient was referred by an ophthalmologist. Therefore, the results will be presented according to a 214 patients sample.

In $79.9 \%$ of the patients referred to the uveitis consultation, inflammation was recognized. However, inflammation was only classified by the SUN Working Group Grading Scheme for Anterior Chamber Cells ${ }^{6}$ in $4.7 \%$ of the cases.

Additionally, only $14.5 \%$ of the cases were classified according to the SUN Working Group Descriptors of Uveitis (anatomy, onset, duration, and course). ${ }^{6}$ Retina specialists, general ophthalmologists, cornea/anterior segment specialists and neuro-ophthalmology specialists were the professionals that correctly used the descriptors. Incomplete uveitis classification was performed in $48.1 \%$ of the cases and $37.4 \%$ of the patients were referred to uveitis specialist without uveitis classification. More detailed information about ophthalmological examination is found in Table 3.

\section{Diagnostic Approach}

At the time of the first uveitis consultation, $65.1 \%$ of patients were referred with an etiological diagnosis, and approximately more than half of them arrived with an adequate infectious panel (52.1\%) and rheumatological panel (58.1\%). Investigation panel differed among anatomical diagnoses; infectious panel was more asked in posterior uveitis, while rheumatologic panel was more requested in panuveitis. General lab test request was greater in posterior uveitis, followed by panuveitis, anterior uveitis and intermediate uveitis.

Only 69 patients required aqueous humor Polymerase Chain Reaction (PCR) study. Nevertheless, solely $11.6 \%$ of these patients had this laboratory requested. Retina specialists, general ophthalmologists, glaucoma specialists, and neuro-ophthalmology specialists requested this test.

More detailed information about the diagnostic approach description is found in Table 4.

\section{Management Approach}

Patients were referred with adequate topical treatment in $65.1 \%$ of the cases. Overall referral with the correct systemic therapy $(n=315)$ was $32 \%$. However, only 250 patients needed systemic treatment, from which $59.6 \%$ were referred to uveitis specialists without the correct therapy.

Systemic therapies in prescription order included immunomodulators, antibiotics for antiparasitic use, biologicals, antivirals, corticosteroids, and antibiotics. Immunomodulators and biological therapies were mostly prescribed by rheumatologists; corticosteroids and antibiotics for antiparasitic use by retina specialists; antivirals by retina specialists; and antibiotics by pediatric rheumatologists.

More detailed information about the management approach description is found in Table 5.

\section{Uvea Specialist Evaluation}

The time required by the uvea specialist to reach a final diagnosis varied between 0 and 94 weeks, with a mean of 5.27 weeks ( 0.1 years). In $81.3 \%$ of the patients, a final etiological diagnosis was reached, $72.3 \%$ corresponded to non-infectious uveitis, and $27.7 \%$ to infectious uveitis. Regarding anatomical classification, anterior uveitis was the most common, followed by panuveitis, posterior uveitis and intermediate uveitis. 
Table 2 Referral Specialists Description

\begin{tabular}{|c|c|c|c|c|}
\hline & \multicolumn{2}{|c|}{$\begin{array}{l}\text { Referring } \\
\text { Specialist }\end{array}$} & \multirow{2}{*}{$\begin{array}{l}\text { Time Between First Symptom or } \\
\text { Episode and Uvea Specialist } \\
\text { Evaluation } \\
\text { Weeks }\end{array}$} & \multirow{2}{*}{$\begin{array}{l}\text { Number of Previous } \\
\text { Ophthalmologists Who } \\
\text { Evaluated the Patient }\end{array}$} \\
\hline & $\mathbf{n}$ & $\%$ & & \\
\hline General & \multicolumn{2}{|c|}{$n=315$} & $108.5 \pm 164.2$ & $1.91 \pm 1.09$ \\
\hline Retina specialist & 111 & 35.2 & $87.6 \pm 128.1$ & $2 \pm 1.09$ \\
\hline General ophthalmologist & 57 & 18.1 & $129.4 \pm 223.8$ & $1.67 \pm 0.92$ \\
\hline Rheumatologist & 45 & 14.3 & $149.1 \pm 179$ & $1.65 \pm 1.05$ \\
\hline Cornea and anterior segment specialist & 28 & 8.9 & $74 \pm 84.8$ & $2.23 \pm 1.11$ \\
\hline Non-informed & 23 & 7.3 & $87.4 \pm 128.8$ & $2.06 \pm 1.55$ \\
\hline Other & 19 & 6 & $144 \pm 221.6$ & $2 \pm 1.22$ \\
\hline Glaucoma specialist & 10 & 3.2 & $79.2 \pm 149$ & $1.67 \pm 0.87$ \\
\hline Pediatric rheumatologist & 8 & 2.5 & $136.3 \pm 161.3$ & $1.86 \pm 0.38$ \\
\hline Oculoplastics specialist & 3 & 1 & 44 & $4 \pm 1.4 \mid$ \\
\hline Pediatric ophthalmologist & 3 & 1 & $87.3 \pm 68$ & $1.33 \pm 0.58$ \\
\hline General practice physician & 2 & 0.6 & 20 & 1 \\
\hline Neurologist & 2 & 0.6 & 4 & 3 \\
\hline Neuro-ophthalmology specialist & 2 & 0.6 & 156 & $\mathrm{I} .5 \pm 0.7 \mathrm{I}$ \\
\hline Internist & 1 & 0.3 & 52 & NA \\
\hline Optometrist & 1 & 0.3 & 520 & 1 \\
\hline \multirow{8}{*}{$\begin{array}{l}\text { Time between first symptom or episode } \\
\text { and uvea specialist evaluation by uveitis } \\
\text { type }\end{array}$} & \multirow{3}{*}{\multicolumn{2}{|c|}{$\begin{array}{l}\text { Causative } \\
\text { diagnosis }\end{array}$}} & \multicolumn{2}{|l|}{$\mathrm{n}=256$} \\
\hline & & & Infectious & $107 \pm 154.5$ \\
\hline & & & Non-infectious & $123.6 \pm 208.6$ \\
\hline & \multirow{5}{*}{\multicolumn{2}{|c|}{$\begin{array}{l}\text { Anatomical } \\
\text { diagnosis }\end{array}$}} & \multicolumn{2}{|l|}{$n=315$} \\
\hline & & & Anterior & $122.65 \pm 180.5$ \\
\hline & & & Intermediate & $65.57 \pm 132.27$ \\
\hline & & & Posterior & $64.31 \pm 132.27$ \\
\hline & & & Panuveitis & $96.4 \pm 133.06$ \\
\hline
\end{tabular}

When evaluating overall diagnostic coincidence $(n=315)$, referral diagnosis was incorrect in $58.7 \%$ of the cases. However, diagnostic coincidence was evaluated when the patient was referred with an initial etiological diagnosis and a final etiological diagnosis was reached by the uvea specialist; 177 patients met the criteria. Diagnostic coincidence was not reached in $26.6 \%$ of the cases. Non-infectious uveitis diagnosis $(63.8 \%)$ was easier to reach than infectious uveitis $(36.2 \%)$.
More detailed information about the uvea specialist evaluation is shown in Table 6.

\section{Discussion}

To the best of our knowledge, we are presenting the first study about the referral process in uveitis patients in Colombia and the second worldwide. ${ }^{7}$

Demographic characteristics of uveitis reported in studies made in tertiary centers of uveitis worldwide 
Table 3 Ophthalmological Examination Description

\begin{tabular}{|c|c|c|c|c|}
\hline & $\begin{array}{l}\text { Intaocular } \\
\text { Inflammation } \\
\text { Recognition }\end{array}$ & $\begin{array}{l}\text { Intraocular Inflammation } \\
\text { Classification According to } \\
\text { the SUN* }\end{array}$ & $\begin{array}{l}\text { Complete Uveitis } \\
\text { Classification According } \\
\text { to the SUN* }\end{array}$ & $\begin{array}{l}\text { Incomplete Uveitis } \\
\text { Classification According } \\
\text { to the SUN* }\end{array}$ \\
\hline & $n=214$ & $n=214$ & $n=214$ & $n=214$ \\
\hline Retina specialist & 98 & 9 & 20 & 52 \\
\hline General ophthalmologist & 42 & I & 7 & 27 \\
\hline $\begin{array}{l}\text { Cornea and anterior } \\
\text { segment specialist }\end{array}$ & 18 & 0 & 3 & 13 \\
\hline Glaucoma specialist & 6 & 0 & 0 & 7 \\
\hline Oculoplastics specialist & 2 & 0 & 0 & 2 \\
\hline Pediatric ophthalmologist & 3 & 0 & 0 & 2 \\
\hline $\begin{array}{l}\text { Neuro-ophthalmology } \\
\text { specialist }\end{array}$ & 2 & 0 & 1 & 0 \\
\hline
\end{tabular}

Abbreviation: SUN*, standardization of uveitis nomenclature. ${ }^{6}$

coincide with our study results. For example, Archarya et al exposed that uveitis incidence is usually higher in female patients ${ }^{8}$ and similarly, Jones et al exposed that uveitis patients' age varies between 16 and 65 years. ${ }^{9}$ Both results agree with the Felfeli et al study, which reported a mean age of $48 \pm 19$ years and a female percentage of $57 .^{7}$

More than one-third of the patients included in this study were referred by retina specialists, followed by general ophthalmologists. Likewise, Felfeli et al reported retina and ophthalmology to be the most common referring specialties. ${ }^{7}$ Due to the small number of uveologists available, patients are usually first referred to the retina specialist or general ophthalmologists and they are the ones who refer the patient to the uvea specialist. This step may represent a delay in referral and diagnostic time, as well as complications secondary to ocular inflammation. A correlation between referral time and complications, as well as visual impairment, has been described in a pediatric population with uveitis. ${ }^{10}$

A meantime of 108.5 weeks (2.08 years) elapsed between the first uveitic episode and the uvea specialist evaluation. Similarly, a study describing the mean uveitis duration in pediatric patients at the moment of assisting to the Massachusetts Eye and Ear Infirmary was 2 years. ${ }^{10}$ Closely, a study reporting ocular complications in pediatric uveitis described a mean time of 1.79 years between uveitis diagnosis made by an ophthalmologist and arrival to the center. ${ }^{11}$ Consultation time might be influenced by a lack of knowledge about the disease diagnosis and treatment approach, and the administrative processes that are performed before assisting to the uveitis consultation. Contrarily, Felfeli et al reported an average waiting time of $49 \pm 49$ days, which might be attributed to a bigger number of available centers for uveitis attention in countries such as Canada. ${ }^{7}$

In the same way, infectious and posterior uveitis were more rapidly referred than the other ones. This might be attributed to a referral by ophthalmologists in most of the cases, making easier the recognition of posterior damage such as toxoplasmic retinochoroidal scars, and a higher request of laboratory tests, while patients with other types of uveitis were referred, not only by ophthalmologists, but by other types of medical practitioners and specialists. Unexpectedly, anterior uveitis was the type that presented the longest referral time. This might be due to the fact that anterior uveitis is usually managed with topical corticosteroids, and until there are no recurrences, patients are usually not referred. Also, some patient records demonstrated that sometimes anterior uveitis is incorrectly diagnosed and mistreated as conjunctivitis. Nevertheless, it is important to consider that the anterior uveitis group of patients was almost seven times greater than the posterior uveitis group, which difficult the comparison. To the best of our knowledge, there are no published data to compare this information.

Neurologists, general practice physicians, oculoplastic specialists, and internists referred in a shorter time. This might be attributed to the preference for a rapid referral 
Table 4 Diagnostic Approach Description

\begin{tabular}{|c|c|c|c|c|}
\hline & $\begin{array}{l}\text { Patients Referred with } \\
\text { Aqueous Humor PCR* } \\
\text { Results }\end{array}$ & $\begin{array}{l}\text { Patients Referred with } \\
\text { an Adequate } \\
\text { Infectious Panel }\end{array}$ & $\begin{array}{l}\text { Patients Referred with } \\
\text { an Adequate } \\
\text { Rheumatologic Panel }\end{array}$ & $\begin{array}{l}\text { Patient Referred with } \\
\text { an Initial Etiological } \\
\text { Diagnosis }\end{array}$ \\
\hline & $n=69$ & $n=315$ & $n=315$ & $n=315$ \\
\hline Retina specialist & 4 & 55 & 56 & 73 \\
\hline General ophthalmologist & 2 & 32 & 35 & 35 \\
\hline Rheumatologist & 0 & 27 & 40 & 36 \\
\hline $\begin{array}{l}\text { Cornea and anterior } \\
\text { segment specialist }\end{array}$ & 0 & 8 & 10 & 16 \\
\hline Non-informed & 0 & 9 & 11 & 11 \\
\hline Other & 0 & 11 & 11 & 13 \\
\hline Glaucoma specialist & I & 5 & 5 & 5 \\
\hline Pediatric rheumatologist & NA & 7 & 7 & 7 \\
\hline Oculoplastics specialist & 0 & 2 & 2 & 3 \\
\hline Pediatric ophthalmologist & 0 & 2 & 1 & I \\
\hline General practice physician & NA & 1 & I & 2 \\
\hline Neurologist & 0 & 2 & 2 & I \\
\hline $\begin{array}{l}\text { Neuro-ophthalmology } \\
\text { specialist }\end{array}$ & I & I & I & 2 \\
\hline Internist & NA & 1 & 0 & 0 \\
\hline Optometrist & NA & 1 & I & 0 \\
\hline \multirow{7}{*}{$\begin{array}{l}\text { Diagnostic approach by } \\
\text { anatomical diagnosis }\end{array}$} & & \multicolumn{3}{|l|}{$n=315$} \\
\hline & & Infectious Panel & Rheumatologic Panel & $\begin{array}{l}\text { General Lab Test } \\
\text { Request }\end{array}$ \\
\hline & & n (\%) & n (\%) & $\%$ \\
\hline & Anterior & $93(46.7)$ & $109(54.8)$ & 50.75 \\
\hline & Intermediate & $7(4 \mid .2)$ & $9(52.9)$ & 47.05 \\
\hline & Posterior & $23(76.7)$ & $19(63.3)$ & 70 \\
\hline & Panuveitis & $39(56.5)$ & $48(69.6)$ & 63.05 \\
\hline
\end{tabular}

Abbreviation: $\mathrm{PCR}^{*}$, Polymerase chain reaction.

since, although these specialists know uveitis causative etiologies and their dangerous consequences, they do not have a deep knowledge of specific ophthalmological management of the uveal diseases. Nevertheless, it is difficult to perform a comparison between specialties, as there was a great variation in the number of patients referred by each one. No published data are available to compare this information.
Although the mean of ophthalmologists evaluating the patients before the uveitis consultation was not high (1.91), the standard deviation shows cases in which patients were evaluated by up to 6 ophthalmologists. This might be attributed to patients that have to consult to multiple specialists as they do not have an answer for their ocular complaints. There are no published data to compare this information. 
Table 5 Management Approach Description

\begin{tabular}{|c|c|c|}
\hline & $\begin{array}{l}\text { Patients } \\
\text { Referred with } \\
\text { an Adequate } \\
\text { Topical } \\
\text { Treatment }\end{array}$ & $\begin{array}{l}\text { Patients } \\
\text { Referred with an } \\
\text { Adequate } \\
\text { Systemic } \\
\text { Treatment }\end{array}$ \\
\hline & $n=315$ & $n=250$ \\
\hline Retina specialist & 67 & 24 \\
\hline General ophthalmologist & 37 & 18 \\
\hline Rheumatologist & 33 & 24 \\
\hline $\begin{array}{l}\text { Cornea and anterior segment } \\
\text { specialist }\end{array}$ & 19 & 7 \\
\hline Non-informed & 15 & 8 \\
\hline Other & 15 & 7 \\
\hline Glaucoma specialist & 6 & 3 \\
\hline Pediatric rheumatologist & 5 & 5 \\
\hline Oculoplastics specialist & 1 & 1 \\
\hline Pediatric ophthalmologist & 2 & 2 \\
\hline General practice physician & 2 & 0 \\
\hline Neurologist & 2 & 2 \\
\hline $\begin{array}{l}\text { Neuro-ophthalmology } \\
\text { specialist }\end{array}$ & 0 & 0 \\
\hline Internist & 0 & 0 \\
\hline Optometrist & 1 & NA \\
\hline \multicolumn{3}{|c|}{ Type of Systemical Treatment Used } \\
\hline & \multicolumn{2}{|l|}{$n=101$} \\
\hline & $\mathbf{n}$ & $\%$ \\
\hline Corticosteroids & 12 & 11.88 \\
\hline Antibiotic for antiparasitic use & 21 & 20.79 \\
\hline Antiviral & 13 & 12.87 \\
\hline Antibiotic & 1 & 0.99 \\
\hline Immunomodulator & 39 & 38.61 \\
\hline Biological & 15 & 14.85 \\
\hline
\end{tabular}

One of the positive points in this study is that inflammation was recognized in almost $80 \%$ of the patients referred to by ophthalmologists. Nonetheless, the SUN Working Group Grading Scheme for Anterior Chamber Cells $^{6}$ is not being adequately used; only some retina specialists and general ophthalmologists graded anterior chamber cells according to this classification. This represents a systematic mistake since it does not allow the uvea specialist to recognize the previous disease course and therapy effectiveness. It would be ideal that each ophthalmologist could classify anterior chamber inflammation by the SUN Working Group Grading Scheme for Anterior Chamber Cells. ${ }^{6}$

On the other hand, in most cases, incomplete use of the SUN Working Group Descriptors of Uveitis $^{6}$ was performed. This implies that even though the classification is known, it has not been completely adopted by ophthalmologists. The complete use of the SUN Working Group Descriptors of Uveitis ${ }^{6}$ would help to determine etiology, the need for treatment change, and patient prognosis in a faster way. Retina specialists, general ophthalmologists, and cornea/anterior segment specialists referred a bigger quantity of patients with an adequate classification of the disease. Thus, we consider these specialties are more related to uveitis patients and could have more extended knowledge of the disease. There are no published data about the use of the SUN classification by ophthalmology subspecialist, ${ }^{6}$ thus, no comparison could be performed.

Almost half of the patients arrived at the uveitis consultation without an adequate request for laboratory tests. Similarly, Felfeli et al reported $53 \%$ of their patients arrived at the uveitis consultation without an adequate test pool, ${ }^{7}$ which delays and difficults proper management and referral. Infectious and rheumatologic panels were adequately requested mostly by internal medicine and pediatric specialties. These specialties are the ones that showed extended knowledge of infectious and autoimmune diseases that can compromise the eye. However, we have to understand that patients with ocular manifestations primarily consult ophthalmologists.

Multiplex PCR is used to discard differential etiologic diagnosis in patients with infectious uveitis. It measures the genomic DNA of Herpesviridae family, Toxoplasma gondii, and mycobacteria. The calculated sensitivity percentage is around $91.3 \%$, specificity $98.8 \%$, positive predictive value $98.6 \%$, and negative predictive value $92.4 \% .{ }^{12}$ Although it is fairly new, it is a very important diagnostic tool of which ophthalmologists should be informed to generate greater use of it. According to our results, retina specialists, general ophthalmologists, glaucoma specialists, and neuro-ophthalmology specialists are the ones who most frequently use this diagnostic method. Nevertheless, our study showed a higher percentage of use of this laboratory test $(11.5 \%)$ than Felfeli et al, that 
Table 6 Uvea Specialist Evaluation Description

\begin{tabular}{|c|c|c|c|}
\hline \multirow{2}{*}{$\begin{array}{l}\text { The time required by the uvea } \\
\text { specialist to reach a final } \\
\text { diagnosis }\end{array}$} & \multicolumn{3}{|c|}{$\begin{array}{l}5.27 \pm 12.98 \text { weeks }(0.10 \pm 0.24 \\
\text { years })\end{array}$} \\
\hline & & $\mathrm{n}$ & $\%$ \\
\hline \multirow[t]{3}{*}{ Final uveitis causative diagnosis } & \multicolumn{3}{|l|}{$n=256$} \\
\hline & Infectious & 71 & 27.73 \\
\hline & Non-infectious & 185 & 72.27 \\
\hline \multirow[t]{5}{*}{ Final uveitis anatomical diagnosis } & \multicolumn{3}{|l|}{$n=315$} \\
\hline & Anterior & 199 & 63.17 \\
\hline & Intermediate & 17 & 5.40 \\
\hline & Posterior & 30 & 9.52 \\
\hline & Panuveitis & 69 & 21.90 \\
\hline \multirow{16}{*}{$\begin{array}{l}\text { Coincidence between referral } \\
\text { specialist diagnosis and uveitis } \\
\text { specialist diagnosis }\end{array}$} & \multicolumn{3}{|l|}{$n=177$} \\
\hline & Retina specialist & \multicolumn{2}{|l|}{43} \\
\hline & $\begin{array}{l}\text { General } \\
\text { ophthalmologist }\end{array}$ & \multicolumn{2}{|l|}{22} \\
\hline & Rheumatologist & \multicolumn{2}{|l|}{24} \\
\hline & $\begin{array}{l}\text { Cornea and } \\
\text { anterior segment } \\
\text { specialist }\end{array}$ & \multicolumn{2}{|l|}{10} \\
\hline & Non-informed & \multicolumn{2}{|l|}{7} \\
\hline & Other & \multicolumn{2}{|l|}{8} \\
\hline & $\begin{array}{l}\text { Glaucoma } \\
\text { specialist }\end{array}$ & \multicolumn{2}{|l|}{4} \\
\hline & $\begin{array}{l}\text { Pediatric } \\
\text { rheumatologist }\end{array}$ & \multicolumn{2}{|l|}{7} \\
\hline & $\begin{array}{l}\text { Oculoplastics } \\
\text { specialist }\end{array}$ & \multicolumn{2}{|l|}{2} \\
\hline & $\begin{array}{l}\text { Pediatric } \\
\text { ophthalmologist }\end{array}$ & \multicolumn{2}{|c|}{ I } \\
\hline & $\begin{array}{l}\text { General practice } \\
\text { physician }\end{array}$ & \multicolumn{2}{|l|}{ I } \\
\hline & Neurologist & \multicolumn{2}{|l|}{ NA } \\
\hline & $\begin{array}{l}\text { Neuro- } \\
\text { ophthalmology } \\
\text { specialist }\end{array}$ & \multicolumn{2}{|l|}{ । } \\
\hline & Internist & \multicolumn{2}{|l|}{ NA } \\
\hline & Optometrist & \multicolumn{2}{|l|}{0} \\
\hline
\end{tabular}

(Continued)
Table 6 (Continued).

\begin{tabular}{|l|l|l|l|}
\hline \multirow{2}{*}{$\begin{array}{l}\text { Diagnostic coincidence } \\
\text { according to uveitis final } \\
\text { diagnosis }\end{array}$} & \multicolumn{4}{|l|}{$\mathbf{n}=1 \mathbf{3 0}$} \\
\cline { 2 - 4 } & Infectious & 47 & 36.15 \\
\cline { 2 - 4 } & Non-infectious & 83 & 63.85 \\
\hline
\end{tabular}

calculated a $2 \%$ use of this diagnostic tool in all their sample. $^{7}$

Approximately half of the patients are arriving with an established diagnostic suspicion. Likewise, Flelfeli et al exposed that $45 \%$ of their patients arrived at the consultation with a suspected etiology. ${ }^{7}$ Nevertheless, although we understand the diagnostic confirmation is made by the uvea specialist, it is always important to have a concept from the referring specialist as it helps the approach to a diagnostic impression.

In $65.1 \%$ of the patients, adequate topical treatment was initiated, which indicates initial treatment is being established. Topical treatment implies a lower systemic compromise and it is known for being used in other ophthalmologic conditions, this is why is widely used. Meanwhile, adequate systemic treatment was initiated only in $41.22 \%$ of the cases. These systemic therapies require strict follow-up by specialties such as internal medicine, rheumatology, infectology, and other subspecialties. We understand that establishing systemic treatment is not an obligation for the general ophthalmologist, but the uvea specialist. Nevertheless, because of the lack of uvea specialists in the medical Colombian system, the responsibility of early referral to establish early management lies in ophthalmologists. This information coincides with data exposed by Felfeli et al, which exposed that $48 \%$ of the patients were referred with topical steroids and $10 \%$ with systemic immunosuppressants. ${ }^{7}$

Acute episodes of the disease can be managed with corticosteroids. Nonetheless, definitive treatment must be established with immunomodulators or antibiotics, depending on the etiology. The use of these systemic medications requires adequate follow-up. This is why, if the classification is not correctly performed, follow-up cannot be assured and treatment cannot be established.

The mean time required by the uvea specialist was 5.27 weeks ( 0.1 years). This time is adequate due to the nature of the disease that needs a very extensive evaluation. However, there is a wide standard deviation, which 
might be attributed to delays in our health system that does not allow the patient to have a continuous and rapid follow-up. It could be as well explained by full agendas of few available uvea specialists and the patients' own decisions to quit consultation. Rosenberg et al showed that in $31 \%$ of the patients, the diagnosis was performed at the time of the first consultation. ${ }^{11}$ Additionally, uvea specialist diagnostic performance was really high. It might not be $100 \%$ because of the reasons mentioned before.

Despite it is not the aim of this study, we realized that the prevalence of non-infectious diseases in the uveitis clinic has increased, in contrast to previous studies of our consultation. ${ }^{13}$ Felfeli et al report a higher prevalence of non-infectious uveitis than infectious uveitis. ${ }^{7}$ We consider that this is secondary to a greater understanding of the need for an ophthalmologist, in this case, the uvea specialist, in the management of rheumatologic patients.

In the same way, we evidenced that diagnostic coincidence was greater in non-infectious uveitis than infectious uveitis. This might be attributed to a higher percentage of patients referred with non-infectious uveitis diagnosis.

\section{Limitations}

There were large differences between the number of patients referred by each specialty, which difficulted the comparison between the groups.

We included patients who are still being studied for their uveitis etiology, so the percentage of patients with a final diagnosis may be underestimated. This is why uvea specialist diagnostic performance may present a slight increase.

\section{Conclusion}

The process of referring patients to uveitis specialists is complex but highly relevant for those who suffer from this pathology. Health professionals' education about awareness of the standardized classification of the disease, the appropriate treatment according to the classification, and early referral to the uveologist with adequate laboratory tests, is the most suitable solution in health systems where the availability of uveitis specialists is limited. We recommend the study of referral and attention approaches such as nurse triage system, accessibility and availability of specialists, open-access scheduling, nurse practitioners, telephone follow-up consultations, email consultations, and questionnaire standardization in the uveitis and Latin American context. Finally, the referral of the patient to the uveologists should not mean that they are the only doctors treating the pathology; these patients' treatment requires a multidisciplinary team composed of rheumatologists, internists, neurologists, infectologists, and other ophthalmology specialists, among others, depending on the etiology.

\section{Abbreviations}

ADLT, Alejandra de-la-Torre; AV, Alejandra Villalobos; JMO, Juliana Muñoz Ortiz; JRG, Juliana Reyes Guanes; MAE, María Andrea Estevez; MRS, Mario RamosSantodomingo; VB, Valentina Balaguera; PCR, polymerase chain reaction; SUN, standardized uveitis nomenclature.

\section{Data Sharing Statement}

The datasets used and/or analyzed during the current study are available by the corresponding author on reasonable request.

\section{Ethics Approval}

This study adheres to the ethical principles for human research established by the Helsinki Declaration, the Belmont Report, and Colombian Resolution 008430 from 1993. The confidentiality of the information has been preserved based on the Habeas data law (Organic Law 1581 of 2012). This investigation was presented to Escuela Superior de Oftalmología del Instituto Barraquer de América's research ethics committee. However, as it is a retrospective study and according to the policies of the institution, it did require a registration process but did not require an ethics committee approval process. It was presented, as well, to Universidad del Norte's research ethics committee, obtaining protocol and research approval.

\section{Consent for Publication}

As it is a risk-free research, researchers are exempt, by the Colombian Resolution 008430 from 1993, from obtaining informed consent.

\section{Acknowledgments}

We thank Universidad del Rosario for their help, guidance, and financial support. We also thank Dr. Víctor Flórez García for his methodological advice.

\section{Author Contributions}

All authors contributed to data analysis, drafting or revising the article, have agreed on the journal to which the article will be submitted, gave final approval of the version 
to be published, and agree to be accountable for all aspects of the work.

\section{Disclosure}

The authors declare that they have no competing interests in this work.

\section{References}

1. Luca C, Raffaella A, Sylvia M, et al. Changes in patterns of uveitis at a tertiary referral center in Northern Italy: analysis of 990 consecutive cases. Int Ophthalmol. 2018;38(1):133-142. doi:10.1007/s10792-0160434-x

2. Rathinam SR, Babu M. Algorithmic approach in the diagnosis of uveitis. Indian J Ophthalmol. 2013;61(6):255-262. doi:10.4103/ 0301-4738.114092

3. What is an ocular immunologist (Uveitis specialist)? [Internet]. Uveitis.org | OIUF; [cited February 17, 2020]. Available from: https://uveitis.org/patients/list-of-specialists/ocular-immunologist/. Accessed December 16, 2020.

4. García Alcolea EE, Herrero Aguirre H, Perdomo Leyva D, Gross Fernández C, Casas Gross S. Evaluación del impacto de la consulta de oftalmología en la atención primaria de salud. Medisan. 2010;14:888-903.

5. Guerrero R, Gallego AI, Becerril-Montekio V, Vásquez J. Sistema de salud de Colombia. Salud pública Méx. 2011;53:s144-55.

6. Jabs DA, Nussenblatt RB, Rosenbaum JT; Standardization of Uveitis Nomenclature (SUN) Working Group. Standardization of uveitis nomenclature for reporting clinical data. Results of the First International Workshop. Am J Ophthalmol. 2005;140(3):509-516.
7. Felfeli T, Christakis PG, Bakshi NK, Mandelcorn ED, Kohly RP, Derzko-Dzulynsky LA. Referral characteristics and wait times for uveitis consultation at academic tertiary care centres in Toronto. Can J Ophthalmol. 2018;53(6):639-645. doi:10.1016/j. jcjo.2018.03.006

8. Acharya NR, Tham VM, Esterberg E, et al. Incidence and prevalence of uveitis: results from the Pacific Ocular Inflammation Study. JAMA Ophthalmol. 2013;131(11):1405-1412. doi:10.1001/jamaophthalmol. 2013.4237

9. Jones NP. The Manchester Uveitis Clinic: the first 3000 patientsepidemiology and casemix. Ocul Immunol Inflamm. 2015;23(2):118126. doi:10.3109/09273948.2013.855799

10. Kump LI, Cervantes-Castañeda RA, Androudi SN, Foster CS. Analysis of pediatric uveitis cases at a tertiary referral center. Ophthalmology. 2005;112(7):1287-1292. doi:10.1016/j.ophtha.2005. 01.044

11. Rosenberg KD, Feuer WJ, Davis JL. Ocular complications of pediatric uveitis. Ophthalmology. 2004;111(12):2299-2306. doi:10.1016/j. ophtha.2004.06.014

12. Sugita S, Ogawa M, Shimizu N, et al. Use of a comprehensive polymerase chain reaction system for diagnosis of ocular infectious diseases. Ophthalmology. 2013;120(9):1761-1768. doi:10.1016/j. ophtha.2013.02.020

13. de-la-Torre A, López-Castillo CA, Rueda JC, Mantilla RD, GómezMarín JE, Anaya J-M. Clinical patterns of uveitis in two ophthalmology centres in Bogota, Colombia. Clin Experiment Ophthalmol. 2009;37(5):458-466. doi:10.1111/j.1442-9071.2009.02082.x
Clinical Ophthalmology

\section{Publish your work in this journal}

Clinical Ophthalmology is an international, peer-reviewed journal covering all subspecialties within ophthalmology. Key topics include: Optometry; Visual science; Pharmacology and drug therapy in eye diseases; Basic Sciences; Primary and Secondary eye care; Patient Safety and Quality of Care Improvements. This journal is indexed on PubMed

\section{Dovepress}

Central and CAS, and is the official journal of The Society of Clinical Ophthalmology (SCO). The manuscript management system is completely online and includes a very quick and fair peer-review system, which is all easy to use. Visit http://www.dovepress.com/ testimonials.php to read real quotes from published authors. 